\title{
Factors and Regional Differences Associated with Endometriosis: A Multi-Country, Case-Control Study
}

\author{
Charles Chapron - Jing-He Lang - Jin-Hua Leng • Yingfang Zhou • \\ Xinmei Zhang $\cdot$ Min Xue $\cdot$ Alexander Popov $\cdot$ Vladimir Romanov · \\ Pascal Maisonobe $\cdot$ Patrick Cabri
}

Received: April 12, 2016/ Published online: June 24, 2016

(C) The Author(s) 2016. This article is published with open access at Springerlink.com

\begin{abstract}
Introduction: The present study aimed to investigate clinical, lifestyle, and environmental factors associated with endometrioma (OMA) and/or deep infiltrating endometriosis (DIE) as determined by
\end{abstract}

Enhanced content To view enhanced content for this article go to http://www.medengine.com/Redeem/8BD4 F060730340E1.

Electronic supplementary material The online version of this article (doi:10.1007/s12325-016-0366-x) contains supplementary material, which is available to authorized users.

C. Chapron $(\square)$

Department of Gynecology and Obstetrics II and Reproductive Medicine, CHU Cochin, Bâtiment Port Royal, 53 avenue de l'Observatoire, 75014 Paris, France

e-mail: charles.chapron@aphp.fr

J.-H. Lang · J.-H. Leng

Department of Obstetrics and Gynecology, Peking Union Medical College Hospital, Chinese Academy of Medical Science and Peking Union Medical College, Beijing, China

Y. Zhou

Peking University First Hospital, Beijing, China

X. Zhang

Women's Hospital School of Medicine, Zhejiang

University, Hangzhou, China case-control comparison [women with superficial peritoneal endometriosis (SUP) or no endometriosis], and compare differences between factor associated with endometriosis at a national level.

Methods: This was three countries (China, Russia, and France), case-control study in 1008 patients. Patients were identified and enrolled during their first routine appointment with their physician post-surgery for a benign gynecologic indication, excluding pregnancy. Retrospective information on symptoms and previous medical history was collected via face-to-face interviews; patients also completed

\section{Xue}

The Third Xiangya Hospital of Central South University, Changsha, China
A. Popov
Moscow Regional Scientific Research Institute, Moscow, Russian Federation
V. Romanov
Research Institute of Maternity and Childhood (V.N. Gorodkov), Ivanovo, Russian Federation
P. Maisonobe $\cdot$ P. Cabri
Ipsen, Boulogne-Billancourt 92100, France 
a questionnaire to provide information on current habits. For every DIE patient recruited $(n=143)$, two women without endometriosis $(n=288)$, two SUP patients $(n=288)$, and two OMA patients $(n=288)$ were recruited.

Results: For the overall population, factors significantly associated $(P \leq 0.05)$ with DIE or OMA [Odds ratio $(\mathrm{OR})>1$ ] were: previous use of hormonal treatment for endometriosis [OR 6.66; 95\% confidence interval (CI) 4.05-10.93]; previous surgery for endometriosis (OR 1.95; 95\% CI 1.11-3.43); and living or working in a city or by a busy area (OR 1.66; 95\% CI 1.09-2.52). Differences between regions with regard to the diagnosis, symptomatology, and treatment of endometriosis exist.

Conclusion: The findings provide insight into potential risk factors for endometriosis and differences between regions in terms of endometriosis management and symptomatology. Further investigations are required to confirm the associations found in this study.

Trial registration: ClinicalTrials.gov identifier, NCT01351051.

Funding: Ipsen.

Keywords: Environmental factors; Diagnosis; Endometriosis phenotypes; Lifestyle factors; Infertility; Multi-national study; Painful symptoms; Risk factors

\section{INTRODUCTION}

Endometriosis is an enigmatic disease characterized by the development of functional endometrial tissue outside the uterine cavity [1]. At a population level, an estimated $2-11 \%$ of women of reproductive age has endometriosis [2, 3] often experiencing substantial burden of disease, including chronic pelvic pain and infertility $[4,5]$.

Symptoms of endometriosis can be non-discriminatory, so the initial indication of disease is normally based on a constellation of symptoms [6]. As such, endometriosis is characterized by long delays in diagnosis [7], with up to $74 \%$ of patients receiving at least one false diagnosis [8]. Histologically, there are three phenotypes of endometriotic lesions: superficial peritoneal endometriosis (SUP), cystic ovarian endometriosis or endometrioma (OMA), and deep infiltrating endometriosis (DIE). The pathogenesis of endometriosis is unclear, and it is unknown why different patients present with SUP, OMA, or DIE lesions, and sometimes all the types present in the same patient. The fact that endometriosis phenotype pathogenesis remains elusive suggests that multifactorial mechanisms are involved [9], including hormonal [10], inflammatory $[11,12]$, immunologic $[13,14]$, genetic [15-17], epigenetic [18], environmental [19], and other influences.

There is a need to recognize whether endometriosis presents in different ways in different populations. Population-based studies exploring the SUP, OMA, and DIE phenotypes have confirmed the genetic heterogeneity of endometriosis [15], but offer little insight into the potential for regional variation.

The FEELING (Factors associated with the development of Endometrioma and dEep infiLtratING endometriosis) study (NCT01351051) aimed to identify clinical, lifestyle, and environmental factors associated with OMA and/or DIE. As the study took place over three diverse geographic regions, differences in endometriosis presentation were also compared descriptively. 


\section{METHODS}

\section{Study Design}

This was three countries, incident case-control study conducted at seven hospital gynecologic departments in China (four centers), Russia (two centers), and France (one center) between May 2011 and April 2013. Females aged 18-41 years who had undergone surgery (laparoscopy or laparotomy) for a benign gynecologic indication in the last 3 months were considered for enrollment at their first routine post-surgical appointment with their usual physician (study visit).

Patients were eligible if they showed either no visible endometriosis lesions (control patient) or histologically confirmed endometriosis lesions. Histologically proven endometriotic lesions were classified into three groups: [20] SUP (control patient), OMA (case patient), or DIE (case patient). Endometriotic lesions were considered as DIE when the muscularis (bladder, intestine, and intrinsic ureter) was infiltrated by endometriotic tissue after radical surgery (e.g., bowel resection, partial cystectomy, and ureteral resection) [21]. For other endometriotic locations [uterosacral ligament(s), vagina, and extrinsic ureter], DIE was arbitrarily defined as endometriotic tissue infiltrating beneath the peritoneum surface deeper than $5 \mathrm{~mm}$ [22]. Patients can exhibit variable degrees of endometriotic infiltration, potentially harboring tissue characteristics of multiple subgroups; thus, patients were arbitrarily classified according to the most severe condition. By definition, endometriotic lesions were ranked from least to worst as follows: SUP, OMA, and DIE [20]. Patients were excluded in the event of pregnancy or if surgical findings showed suspicion or evidence of malignancy. To ensure absolute certainty of the presence or the absence of endometriosis, patients lacking histologic confirmation of endometriosis were ineligible [20].

Investigators enrolled all consecutive patients fulfilling the eligibility criteria during the specified period ( $\sim 2$ years). The planned enrollment was 546 patients in China, 308 patients in Russia, and 154 patients in France, with half as many DIE patients recruited to SUP, OMA, or no endometriosis patients at each center. Cases and controls were recruited to achieve the targeted recruitment numbers for each group and to maintain the group ratio within each site along the recruitment process. Furthermore, within each site, DIE patients with uterosacral lesions could only comprise $20 \%$ of the DIE population. There were no matching factors.

Enrolled patients participated in a face-to-face interview with the investigator at the study visit to obtain retrospective data on symptoms and previous medical history, including pre-surgical complaints, endometriosis surgery details, endometriosis status, endometriosis history, additional medical history, gynecologic history, and family medical history using an internet-based electronic data capture (EDC) case report form (Supplemental Data Table S1). Patients then completed a paper questionnaire to provide prospective information on their current habits, including environment, dietary habits, and health and mood during the post-surgical visit (Supplemental Data Table S2). Investigators also completed a questionnaire using EDC (age, gender, years in practice in gynecology, practice site information, number of newly diagnosed subjects with endometriosis per year, total number of endometriosis cases followed per year, and number of assisted reproductive technologies for endometriosis per year). The investigator was responsible for 
the validity of all data collected at each site. A study sponsor monitor regularly checked that the data were accurately reported. Documents, including questionnaires (non-validated), were translated at a country level to ensure accuracy and cultural competency.

\section{Objectives and Assessments}

The primary objective of this study was to identify clinical, lifestyle, and environmental factors associated with OMA and/or DIE, as determined by case-control comparison. Evidence suggests that SUP may occur intermittently in all women and may not represent true endometriotic disease [23]; thus, because uncertainties arise regarding the precise clinical significance of SUP [9], for the purpose of the primary analysis, both women with no endometriosis and women with SUP were considered control cases. As suggested by Holt and Weiss [24], in this study, only the ovarian (OMA) and deep forms (DIE) were considered as 'definite disease' (case group). The primary analysis was to determine whether significant differences emerged between OMA or DIE vs SUP and no endometriosis groups when the following variables were analyzed: demographics, pre-surgery complaints, endometriosis history, associated diseases, uterine surgical history, menstrual and ovulation history, contraception history, gestation and parity, birth data, family medical history, environment, dietary habits, health, and mood. The secondary objective was to identify factors associated with endometriosis, including the determination of any comparative differences between descriptive variables emerging at a national level and the analysis of patient profiles by endometriosis status in women who had recently undergone surgery for a benign gynecologic indication. Some variables were analyzed for regional differences across different endometriosis phenotypes.

Besides the completion of the patient and investigator questionnaires, no additional assessments, tests, or safety evaluations were performed. The decision to perform surgery was made according to local routine clinical practice, prior to and independently from the decision to enroll the patient into the study. The study did not interfere with any decision made by the physician related to therapeutic management. Histologic evaluation was performed locally at each study hospital.

\section{Statistical Analysis}

It was planned to enroll a total of 1008 patients (no endometriosis $n=288$; SUP $n=288$; OMA $n=288$; DIE $n=144$ ) to detect odds ratios (ORs) $\geq 2$ with a significance level of $5 \%$ and a power of $90 \%$, and allowing for $20 \%$ missing/ non-evaluable questionnaires.

In the primary analysis, patients with SUP were regarded as controls and pooled with the no endometriosis group because of the uncertainties surrounding the real clinical significance of SUP [9]. Likewise, OMA and DIE were considered 'definite disease' and pooled [24].

Univariate logistic regression analyses were performed at the first stage to screen all factors potentially associated with OMA or DIE. All variables with a $P$ value below the $20 \%$ significance level in the univariate regressions were retained for the subsequent correlation analyses. Association between these retained variables was then tested using the appropriate method, depending on the nature of the variables. Association between a quantitative variable and a qualitative one was tested using an analysis of variance with the quantitative 
variable as the dependent variable and the qualitative variable as the covariate. The association between two continuous variables was tested using the Spearman correlation coefficient. The association between two qualitative variables was tested using Chi-square test, or Fisher's exact test [if expected count $(s)<5]$. Significant associations were determined at a $P<0.0001$ level. In the case of a strongly significant association between two variables, the variable to keep for the multivariate regression was selected based on a clinical rationale by the principal investigator and the study team (comprising the medical director, project manager, and statistician).

These variables, as well as the variables 'hormonal treatment for endometriosis', 'infertility', and 'previous surgical diagnosis', were then introduced in the construction of the final multivariate logistic regression model. A stepwise elimination analysis was followed using a significance level of $10 \%$ to entry variables in the model and a significance level of $5 \%$ to retain variables in the model. The Hosmer and Lemeshow goodness-of-fit test for the final selected model was presented, and 95\% confidence intervals (CI) for the OR, estimated by the logistic model, were calculated [25].

Comparisons between countries for qualitative variables were conducted using Chi-squared tests.

All statistical analyses were performed by the biostatistics unit of LINCOLN using the SAS ${ }^{\circledR}$ software, version 9.1 (SAS Institute Inc., Cary, North Carolina, USA, 2004).

\section{Compliance with Ethics Guidelines}

All procedures followed were in accordance with the ethical standards of the responsible committee on human experimentation (institutional and national) and with the Helsinki Declaration of 1964, as revised in 2013.

Patients provided written informed consent to allow their medical data to be collected, analyzed, and shared with regulatory authorities. The study identifier for clinicaltrials.gov is NCT01351051. Prior to initiating the study, the investigator/ institution had approval from the Independent Ethics Committee/Institutional Review Board as applicable in the country of study

\section{RESULTS}

\section{Patients}

In total, 1008 surgically screened patients were enrolled between May 26, 2011 and April 30, 2013 and 1007 were analyzed [one DIE patient from Russia was not evaluated (age outside range)]. Baseline characteristics and endometriosis phenotype distribution are presented in total and by country in Table 1 .

\section{Primary Objective}

\section{Factors Associated with OMA or DIE}

Clinical, lifestyle, and environmental factors found to be potentially associated with OMA or DIE in the overall population and by country are presented in Table 2 (univariate analysis) and Table 3 (multivariate analysis). In the overall population, factors significantly associated $(P \leq 0.05)$ with DIE or OMA $(\mathrm{OR}>1)$ were: the previous use of hormonal treatment for endometriosis (OR 6.66; 95\% CI 4.05-10.93), the previous history of surgery for endometriosis (OR 1.95; 95\% CI 1.11-3.43), and living in a city or by a busy area (OR 1.66; 95\% CI 1.09-2.52). Of note, data indicate that predictive factors may vary between different 
Table 1 Baseline characteristics

\begin{tabular}{|c|c|c|c|c|}
\hline Characteristic & $\begin{array}{l}\text { China } \\
(n=546)\end{array}$ & $\begin{array}{l}\text { Russia } \\
(n=307)\end{array}$ & $\begin{array}{l}\text { France } \\
(n=154)\end{array}$ & $\begin{array}{l}\text { Total } \\
(N=1007)\end{array}$ \\
\hline Mean age (years) on visit day (range) & $31.80(18-41)$ & $30.28(19-41)$ & $31.58(18-41)$ & $31.30(18-41)$ \\
\hline Mean $\mathrm{BMI} \pm \mathrm{SD}, \mathrm{kg} / \mathrm{m}^{2}$ & $21.37 \pm 3.27$ & $22.22 \pm 4.01$ & $22.23 \pm 4.07$ & $21.76 \pm 3.66$ \\
\hline \multicolumn{5}{|l|}{ Ethnicity (\%) } \\
\hline Asian & $546(100)$ & 0 & $4(2.6)$ & $550(54.6)$ \\
\hline Caucasian/white & 0 & $306(99.7)$ & $124(80.5)$ & $430(42.7)$ \\
\hline Black/African American & 0 & 0 & $14(9.1)$ & $14(1.4)$ \\
\hline Other & 0 & $1(0.3)$ & $12(7.8)$ & $13(1.3)$ \\
\hline \multicolumn{5}{|l|}{ Marital status, $n / N(\%)$} \\
\hline Single & $80(14.7)$ & $43(14.0)$ & $52(33.8)$ & $175(17.4)$ \\
\hline Married & $450(82.4)$ & $204(66.4)$ & $47(30.5)$ & $701(69.6)$ \\
\hline Free union* & $14(2.6)$ & $44(14.3)$ & $47(30.5)$ & $105(10.4)$ \\
\hline Divorced/separated & $2(0.4)$ & $15(4.9)$ & $7(4.5)$ & $24(2.4)$ \\
\hline Widowed & 0 & $1(0.3)$ & $1(0.6)$ & $2(0.2)$ \\
\hline \multicolumn{5}{|l|}{ Education level, $n / N^{\dagger}$ (\%) } \\
\hline Primary school & $20(3.7)$ & $3(1.0)$ & 0 & $23(2.3)$ \\
\hline High school & $112(20.6)$ & $2(0.7)$ & $7(4.5)$ & $121(12.0)$ \\
\hline Vocational or professional school & $59(10.8)$ & $39(12.7)$ & $7(4.5)$ & $105(10.4)$ \\
\hline Polytechnic or equivalent ( +2 years) & $38(7.0)$ & $21(6.8)$ & $31(20.1)$ & $90(8.9)$ \\
\hline University or business school ( +4 to 5 years) & $316(58.0)$ & $242(78.8)$ & $109(70.8)$ & $667(66.3)$ \\
\hline Missing & 1 & 0 & 0 & 1 \\
\hline \multicolumn{5}{|l|}{ Smoking status, $n / N(\%)$} \\
\hline Smoker & $12(2.2)$ & $50(16.3)$ & $45(29.2)$ & $107(10.6)$ \\
\hline Never smoker & $530(97.1)$ & $200(65.1)$ & $91(59.1)$ & $821(81.5)$ \\
\hline Ex-smoker & $4(0.7)$ & $57(18.6)$ & $18(11.7)$ & $79(7.8)$ \\
\hline \multicolumn{5}{|l|}{ Endometriosis type (\%) } \\
\hline No endometriosis & $156(29)$ & $88(29)$ & $44(29)$ & $288(29)$ \\
\hline SUP, $n$ & $156(29)$ & $88(29)$ & $44(29)$ & 288 (29) \\
\hline OMA, $n$ & $156(29)$ & $88(29)$ & $44(29)$ & $288(29)$ \\
\hline DIE, $n$ & $78(14)$ & $43(14)$ & $22(14)$ & $143(14)$ \\
\hline
\end{tabular}

BMI body mass index, DIE deep infiltrating endometriosis, OMA endometrioma, SD standard deviation, SUP superficial peritoneal endometriosis

${ }^{*} \mathrm{~A}$ union that lacks any publicly recognized bond

${ }^{\dagger} n=1006(n=545$ for China $)$ 


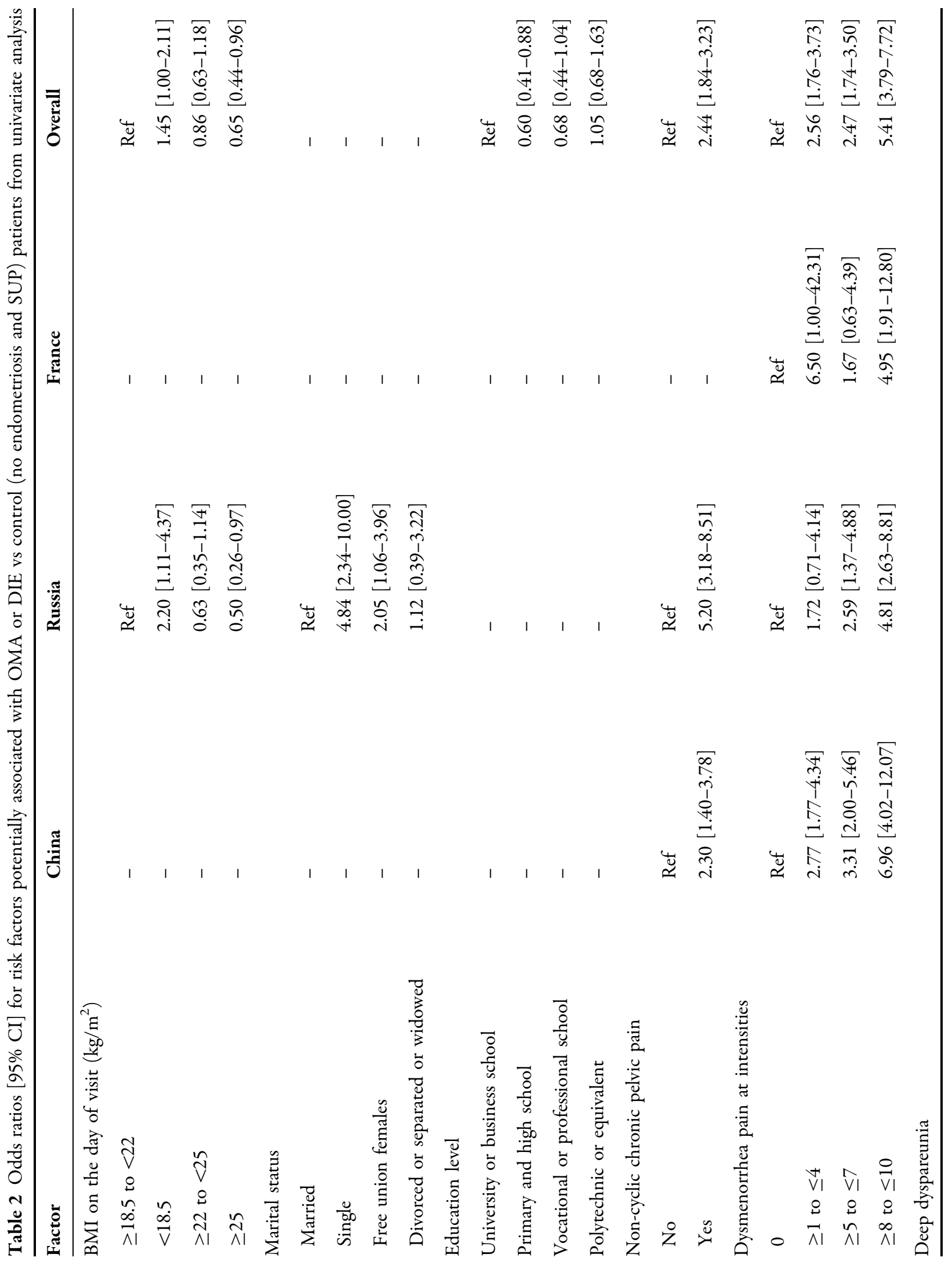




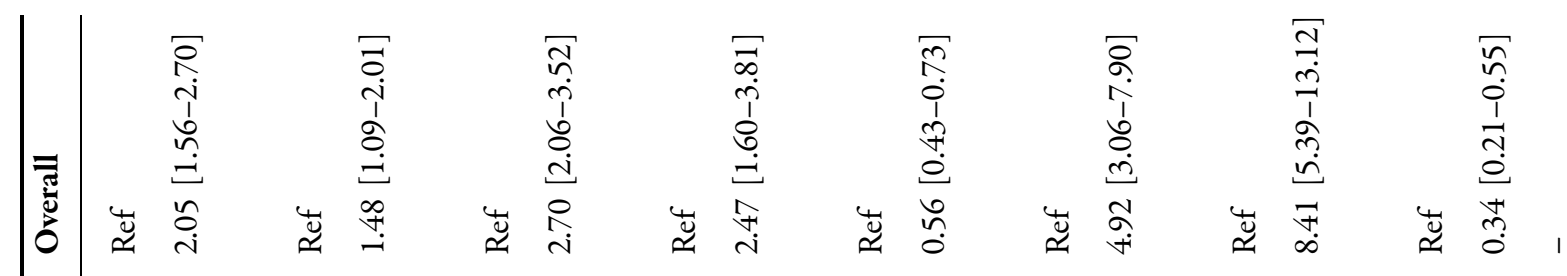

苟

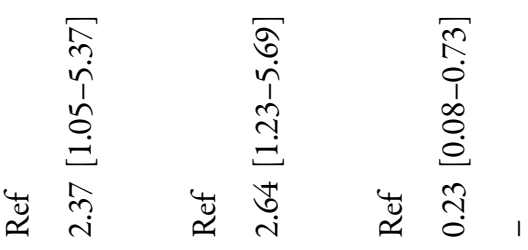

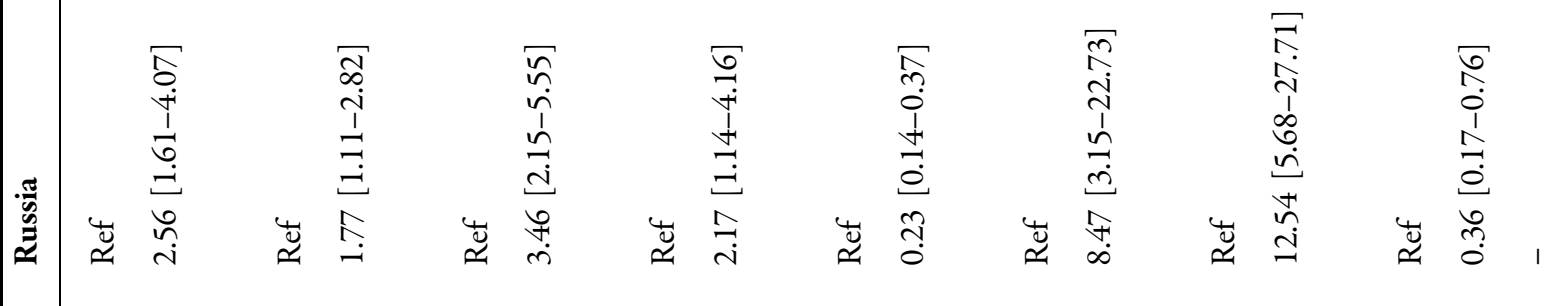

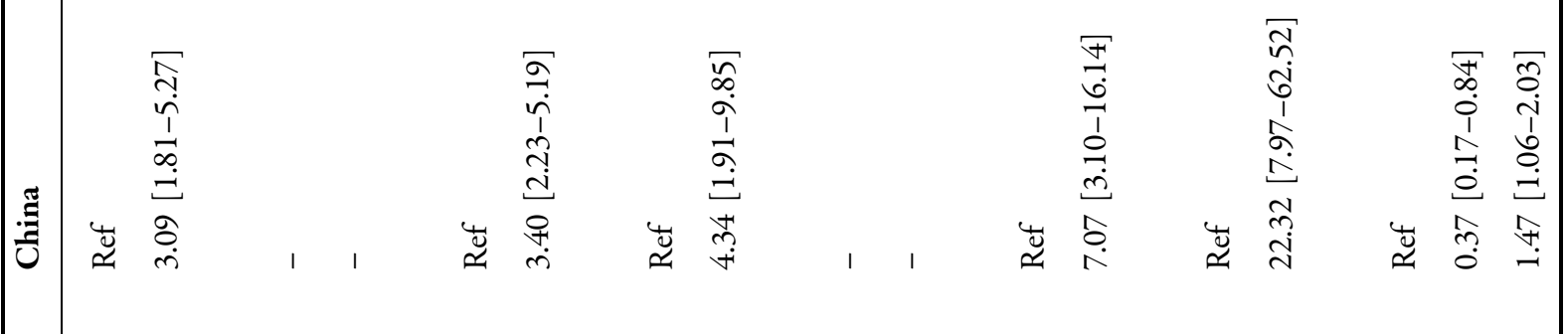

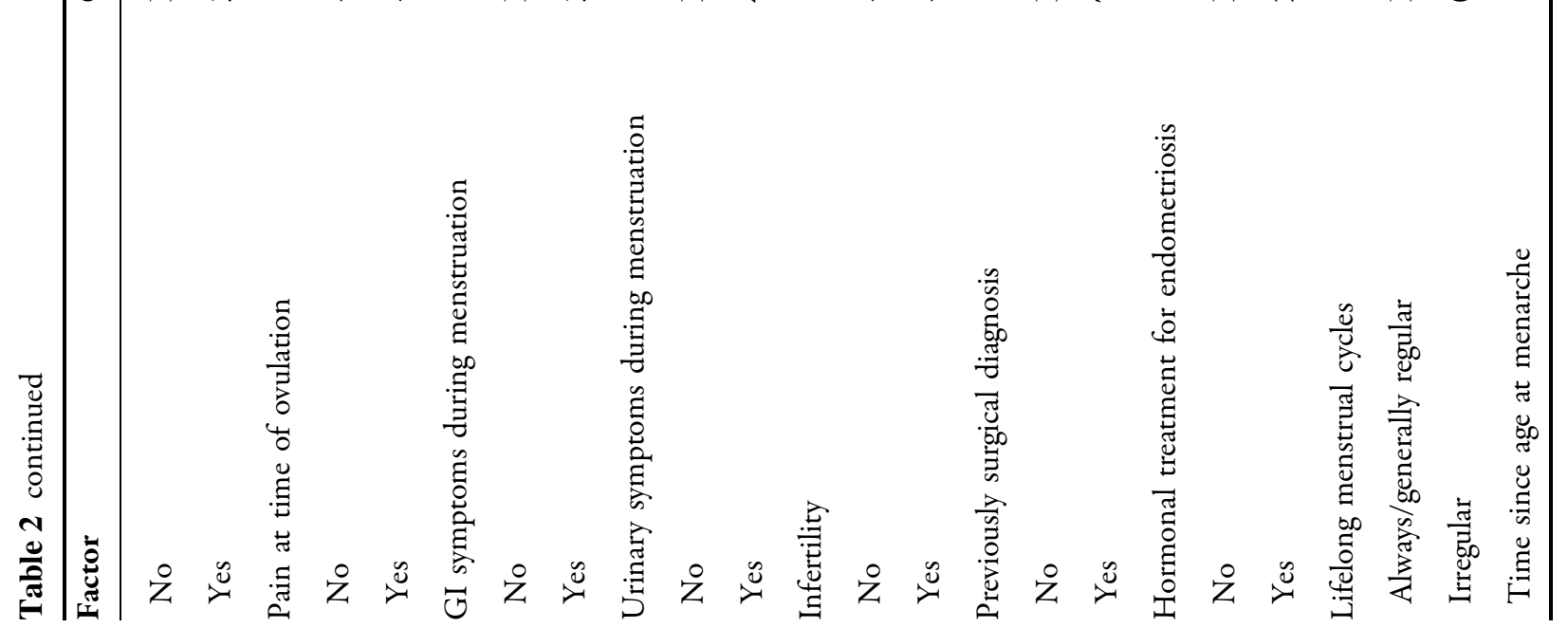




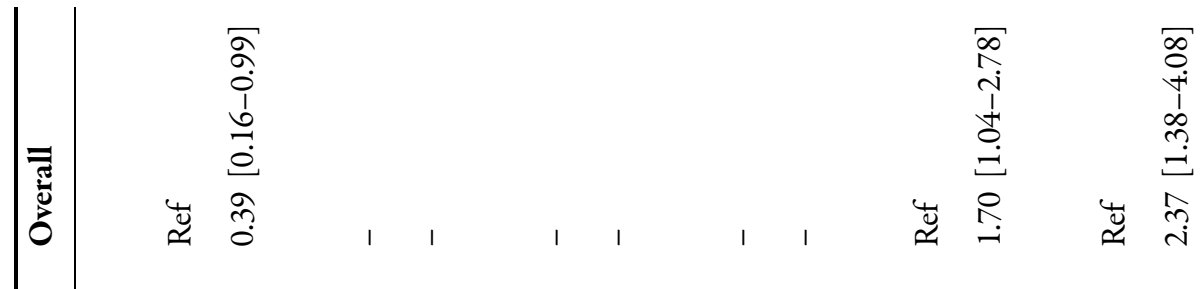

苞

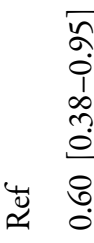

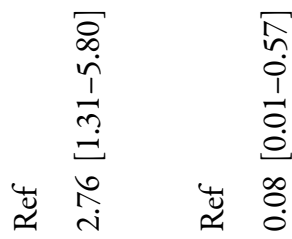

爱

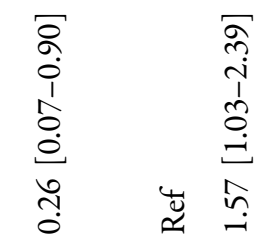

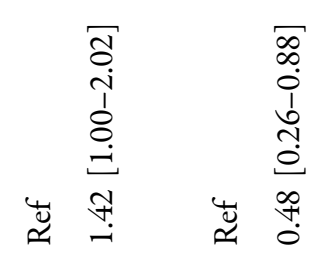

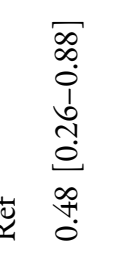

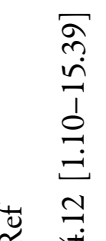

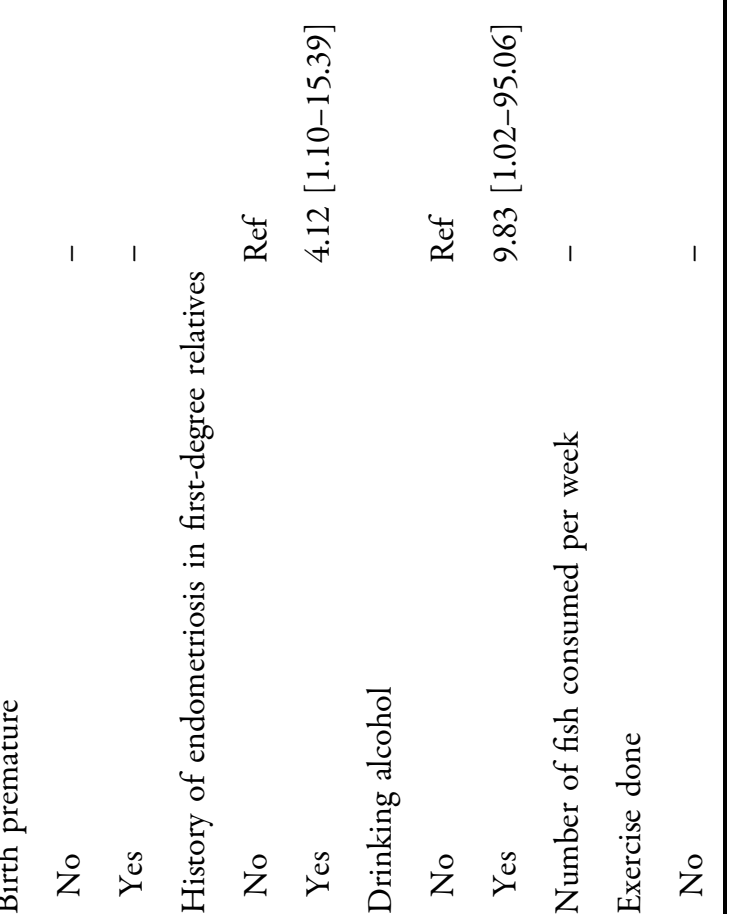

ชี

崩

(n)

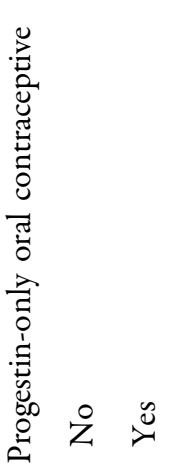

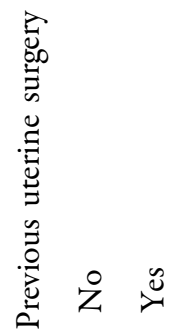

岕 


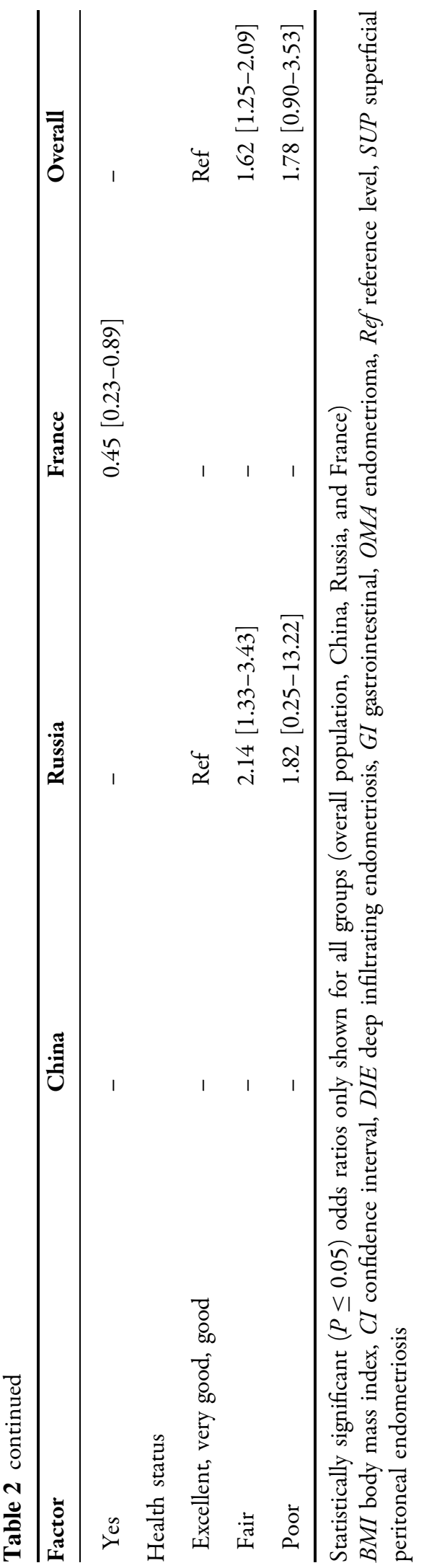

countries, such as greater importance of the previous use of hormonal treatment in China (OR 17.95; 95\% CI 5.92-54.43), or gastrointestinal symptoms during menstruation in China (OR 3.18; 95\% CI 1.90-5.31) and Russia (OR 3.85; 95\% CI 2.13-6.97).

\section{Secondary Objectives-Overall Population}

At study entry, for the overall population, a suspicion of endometriosis was the surgical indication for $51.3 \% \quad(n=517)$ of patients. Following surgery, endometriosis was histologically confirmed in $71.4 \%(n=719)$ of patients leading to a rate of unsuspected endometriosis of $20.1 \%$ ( $n=202$ patients). In the cases of unsuspected endometriosis, the final histologic diagnosis was SUP in the majority of cases, with similar values observed in each of the three countries.

\section{Secondary Objectives-Comparative Differences Between Regions}

\section{Gynecologic History}

Table 4 summarizes the gynecologic history of patients in China, Russia, and France. Differences were seen between countries with regard to regular menstrual cycles, regular use of tampons, vaginal douching practice, menstrual and ovulatory disorders, contraception use, previous pregnancy, and infertility. For all but pregnancy and infertility, these variables were highest in French patients; pregnancy was highest in Chinese patients, and infertility highest in Russian patients.

Infertility was reported in fewer subjects in the OMA group (27.1\%) compared with the DIE (42.0\%), SUP (51.4\%), and control (39.9\%) groups. Infertility occurred in approximately one-third of patients in China regardless of 


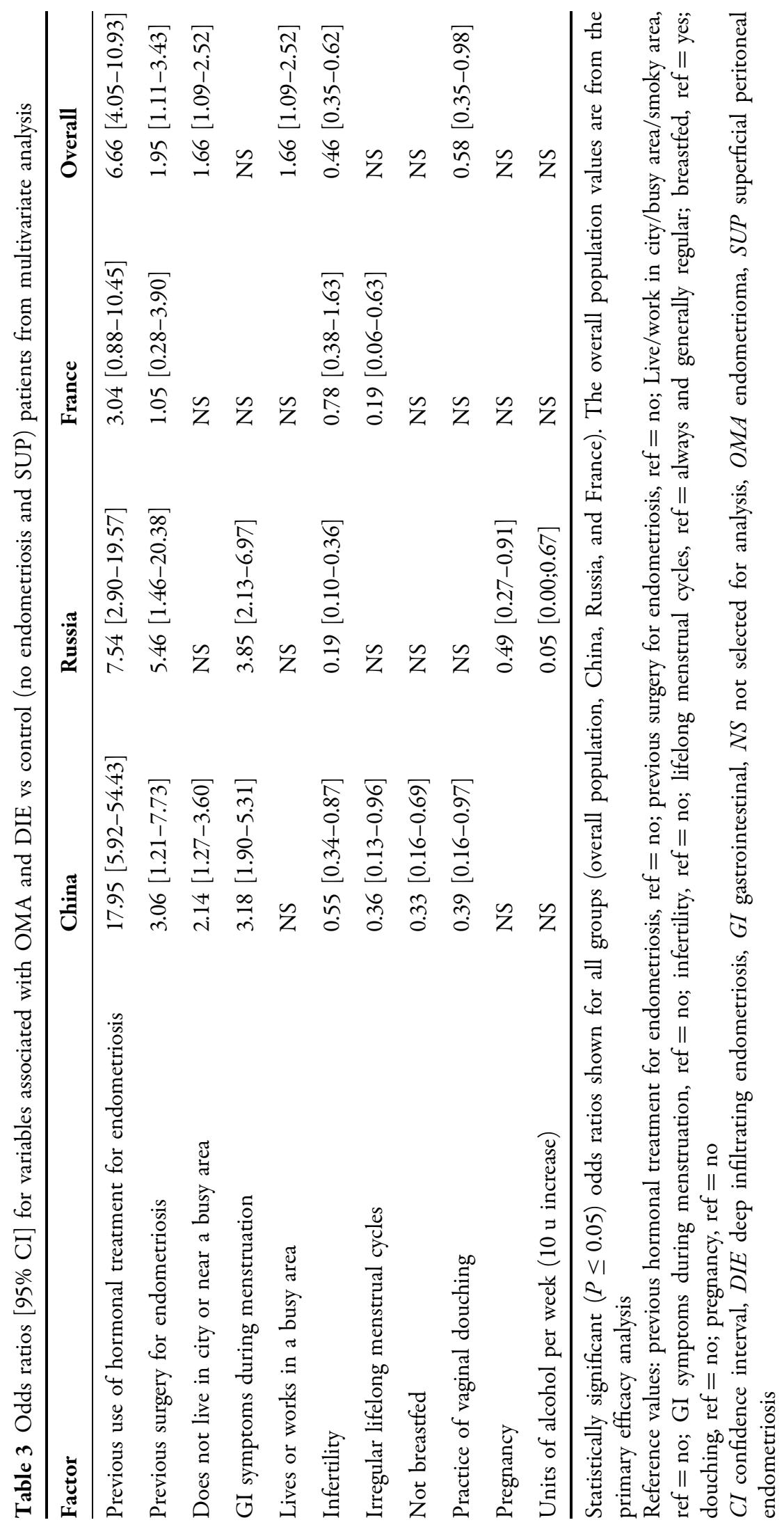




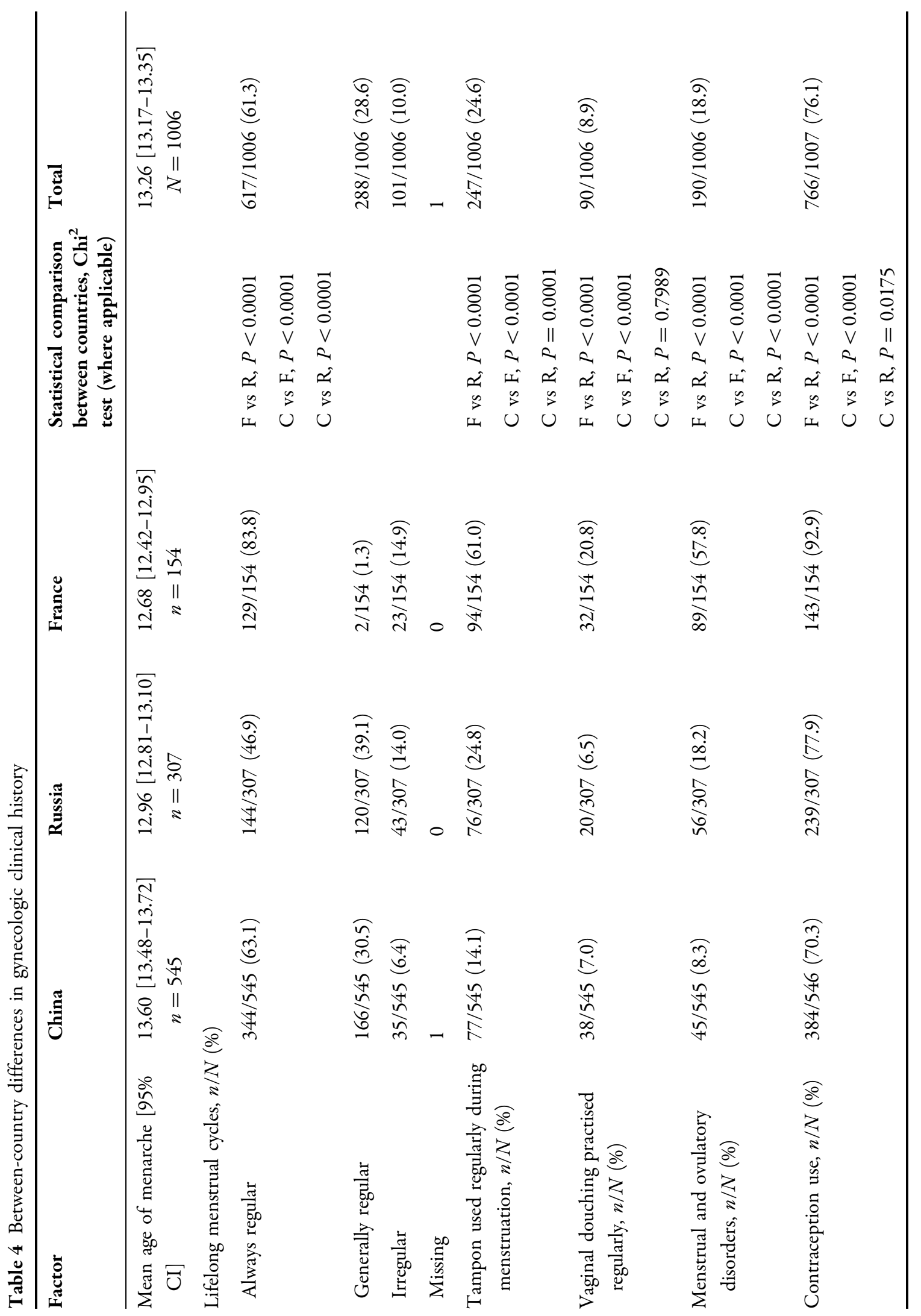




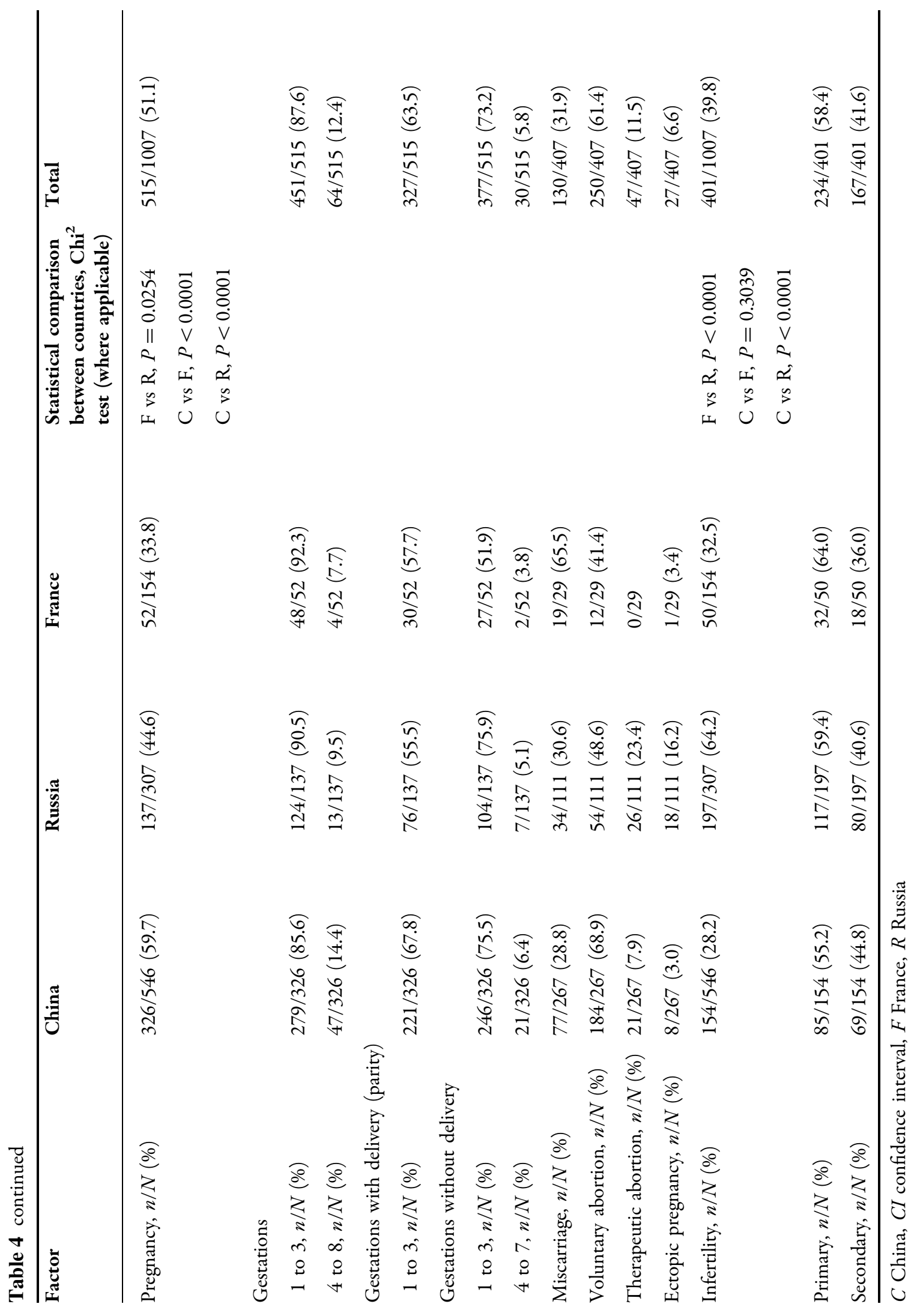




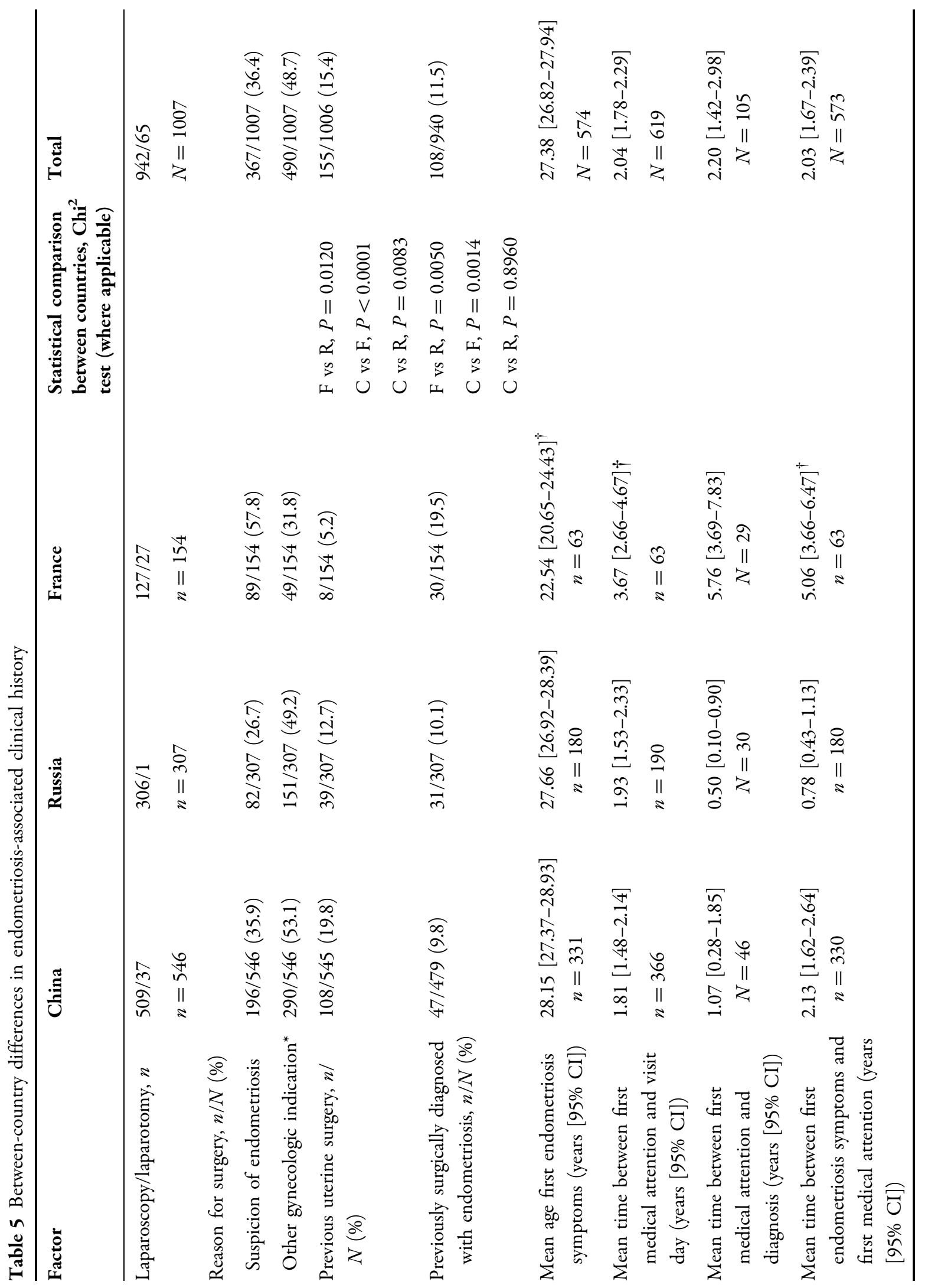




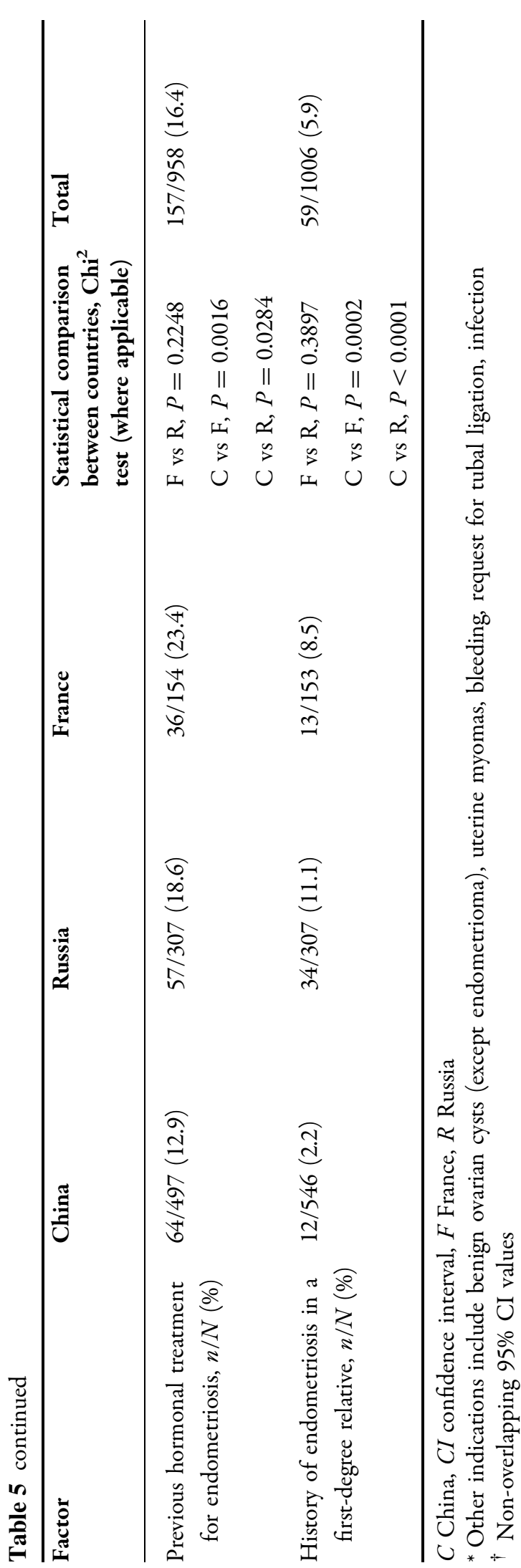

phenotype (OMA, SUP, or DIE) and, in France, in approximately one-quarter with OMA and $40 \%$ with SUP or DIE. However, in Russia, most patients with SUP or DIE had infertility $(86.4 \%$ and $62.8 \%$, respectively), but only one-third of patients with OMA.

\section{Endometriosis History}

In terms of endometriosis history (Table 5), mean [ \pm standard deviation (SD)] age of subjects at the presentation of their first endometriosis symptoms was lower in France $(22.54 \pm 7.50$ years $)$ compared with China $(28.15 \pm 7.22$ years) and Russia (27.66 \pm 5.01 years). The mean \pm SD time between first endometriosis symptoms and first medical attention sought was considerably shorter in Russia $(0.78 \pm 2.38$ years) compared with China $(2.13 \pm 4.67$ years $) \quad$ and France $(5.06 \pm$ 5.58 years). Similarly, the mean $\pm S D$ time between first seeking medical attention and diagnosis was shorter in Russia $(0.50 \pm$ 1.07 years) compared with China (1.07 \pm 2.64 years) and France $(5.76 \pm 5.45$ years $)$. Finally, the mean $\pm \mathrm{SD}$ time since first endometriosis symptoms and the visit day was shorter in Russia $(2.76 \pm 3.88$ years) compared with China ( $4.08 \pm 5.56$ years) and France (8.73 \pm 6.79 years).

The previous uterine surgery was highest in China, while more patients in France were previously surgically diagnosed with endometriosis, and hormonal treatment for endometriosis was also highest in France. Finally, more patients in Russia had a history of endometriosis in a first-degree relative.

\section{Pre-Surgery Symptoms}

Differences in pain reporting were observed between countries, with an overall trend towards the highest symptom reporting in the French group and the lowest symptom 


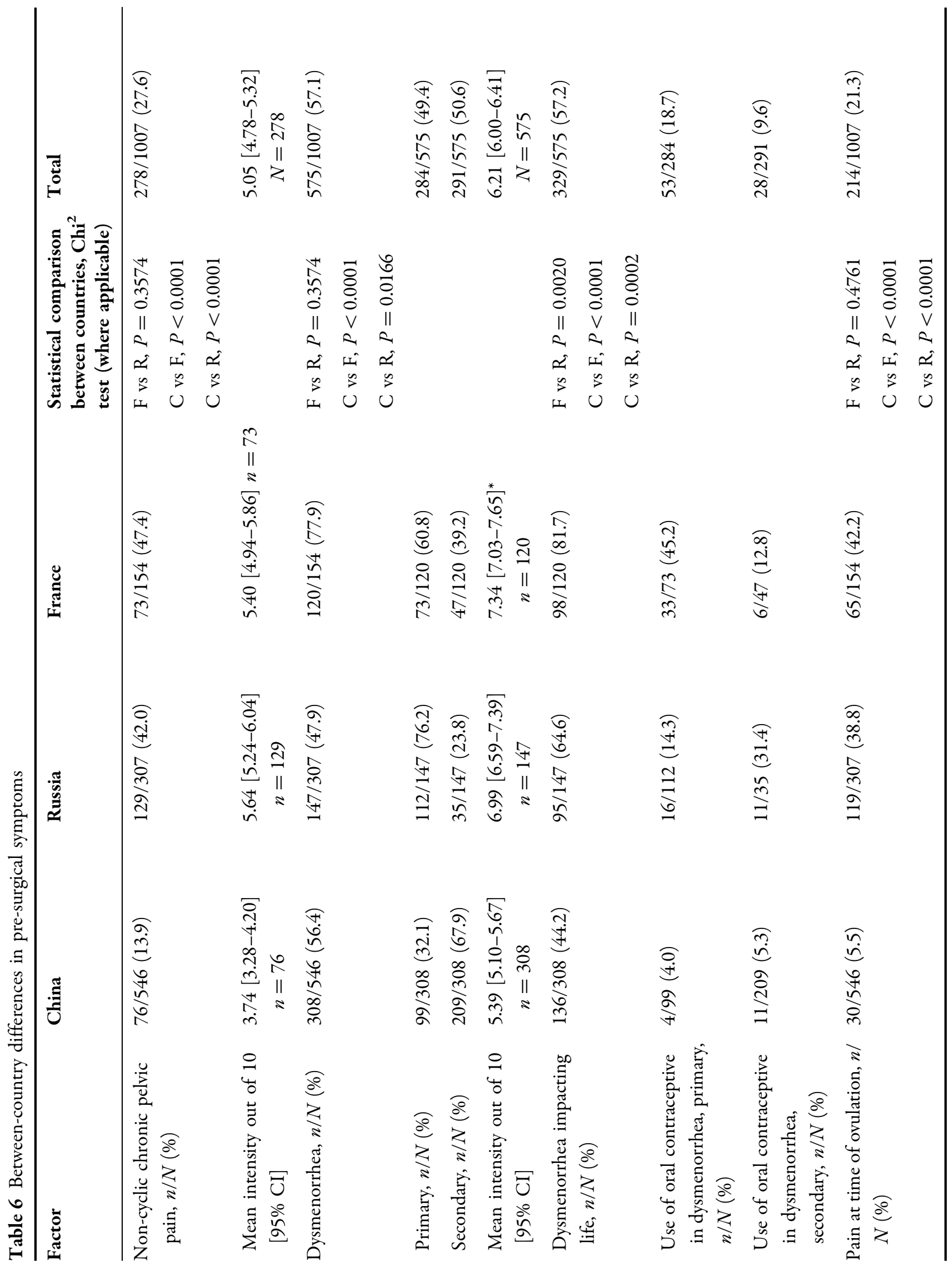




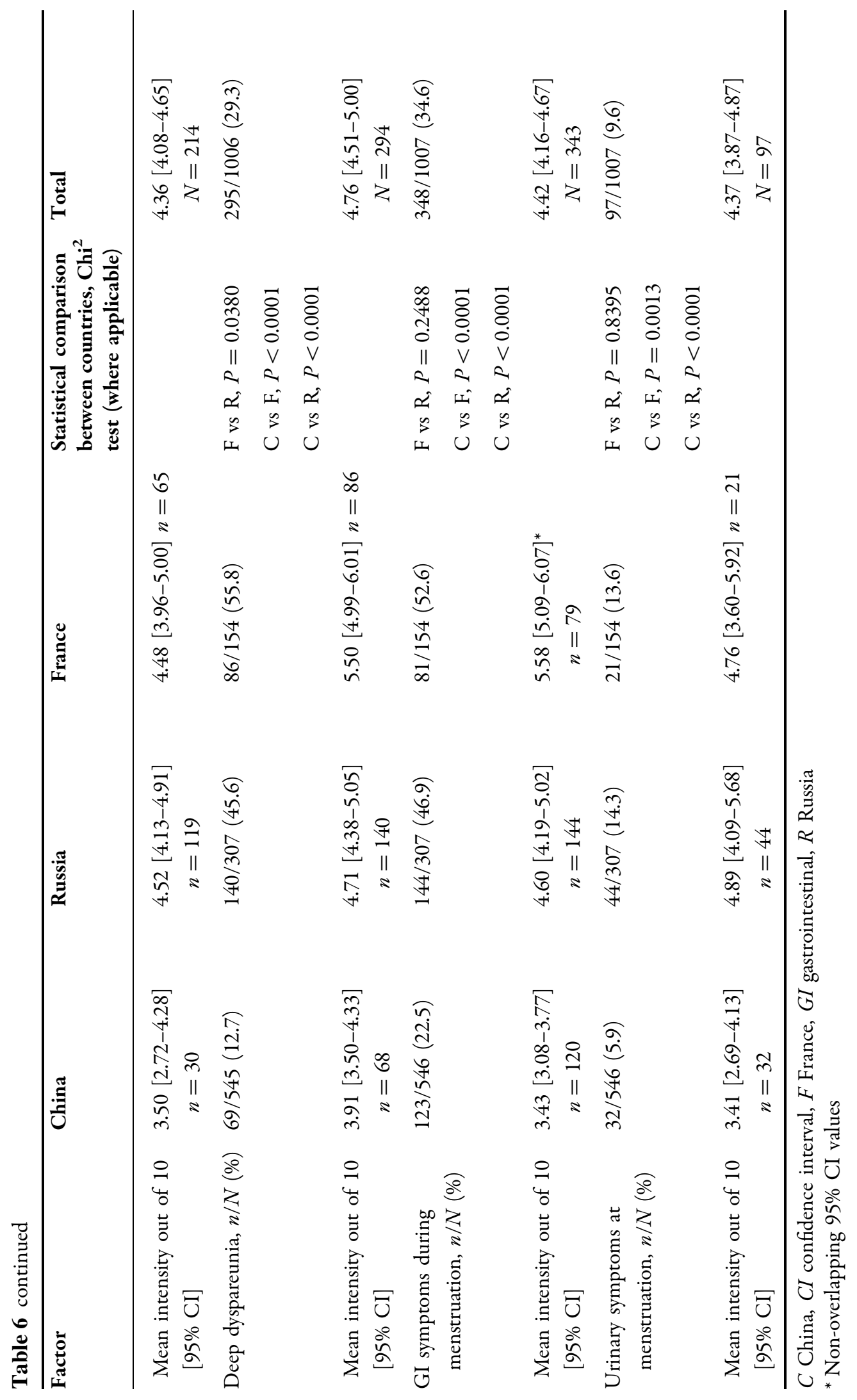


reporting in the Chinese group (Table 6). In the overall population of patients, $57.2 \%(n=329)$ considered dysmenorrhea to have a real impact on their daily quality of life. This impact was significantly more important in France $(81.7 \%$, $n=98)$, compared with Russia $(64.6 \%, n=95)$ and China $(44.2 \%, n=136)$. In the overall population, oral contraception was prescribed to treat intensity of primary dysmenorrhea in $18.7 \%$ of the cases $(n=53)$. This result is significantly correlated to the country: $4.0 \%$ in China $(n=4), 14.3 \%$ in Russia $(n=16)$, and $45.2 \%$ in France $(n=33)$ (Table 6).
In the overall population, painful symptoms were more frequently reported in patients with endometriosis when compared to those without endometriosis. The frequency of painful symptoms seemed to be correlated with the endometriosis phenotype and increased with the severity of the lesions: SUP, OMA, and DIE (Fig. 1a). Similar trends were observed for the intensity of pain/discomfort symptoms according to the visual analog scale, with Chinese patients reporting the lowest intensities (Fig. 1b). While the incidence of symptoms appeared to be correlated with

\section{A}

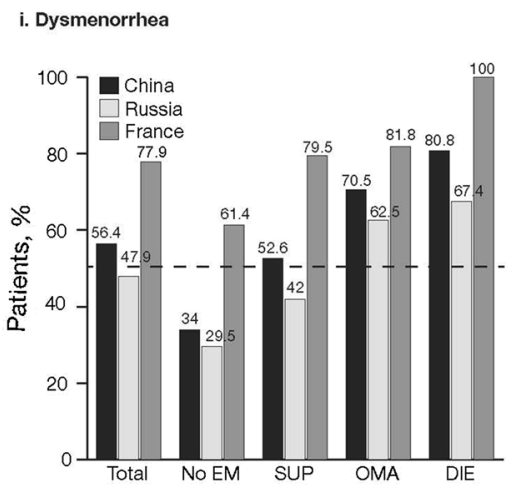

ii. Deep dyspareunia
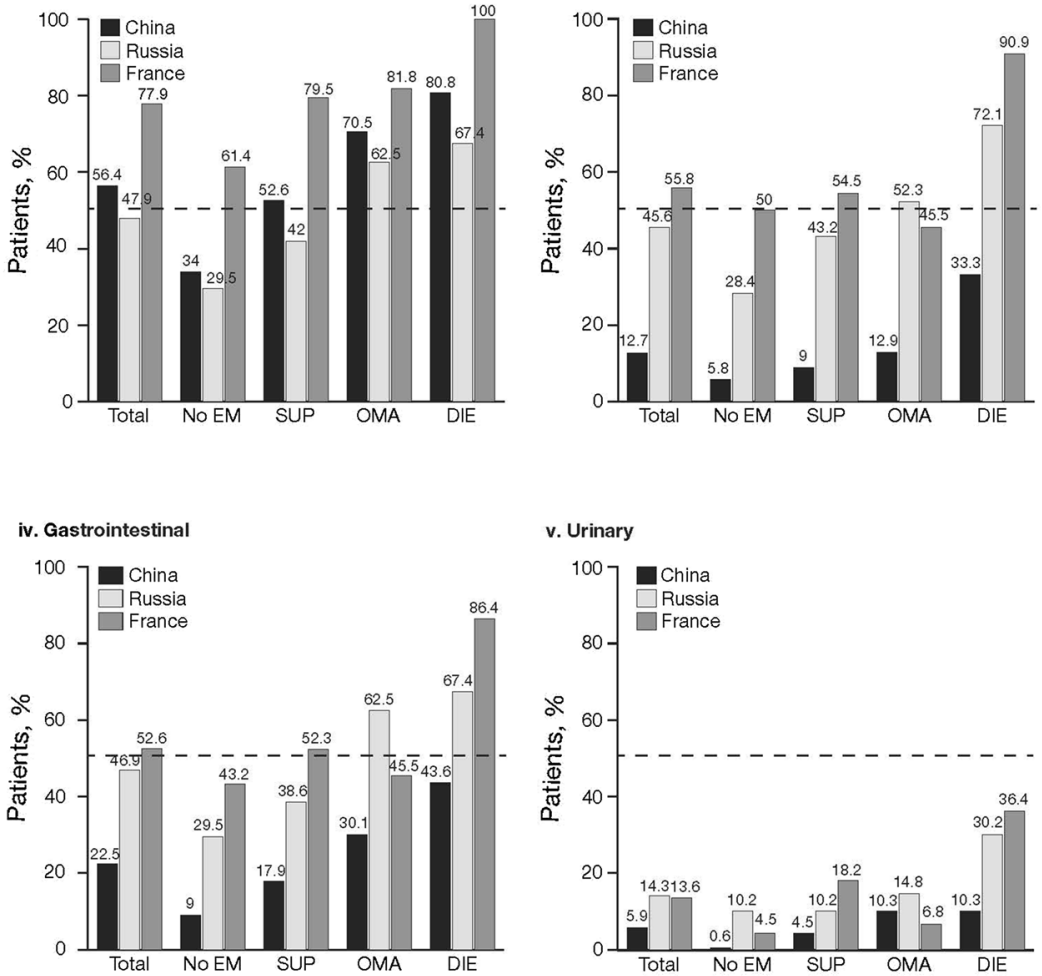

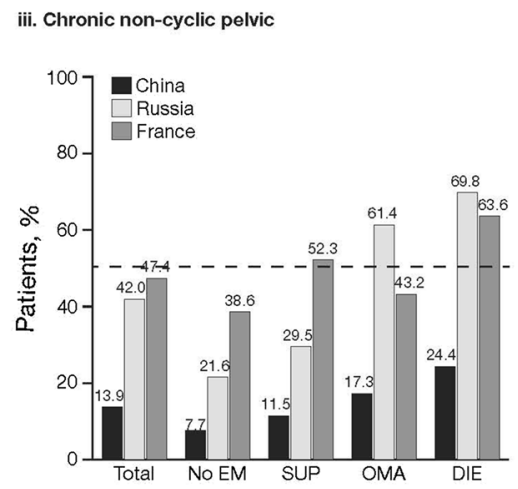

Fig. 1 a Complaint frequency illustrated by endometriosis type and country for $(i)$ dysmenorrhea, (ii) deep dyspareunia, (iii) chronic non-cyclic pelvic pain, (iv) gastrointestinal symptoms during menstruation, and $(v)$ urinary symptoms during menstruation. b Pain or discomfort intensity as rated on Visual Analog Scale for $(i)$ chronic non-cyclic pelvic pain, (ii) dysmenorrhea, (iii) deep dyspareunia, (iv) gastrointestinal symptoms during menstruation, and $(v)$ urinary symptoms during menstruation. EM endometriosis, DIE deep infiltrating endometriosis, OMA endometrioma, SUP superficial peritoneal endometriosis 


\section{B}
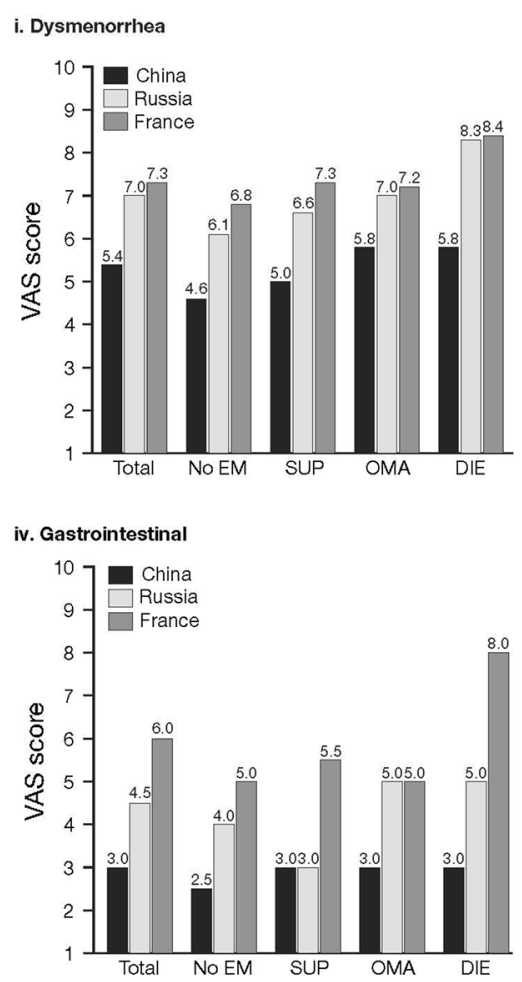

VAS, visual analog scale

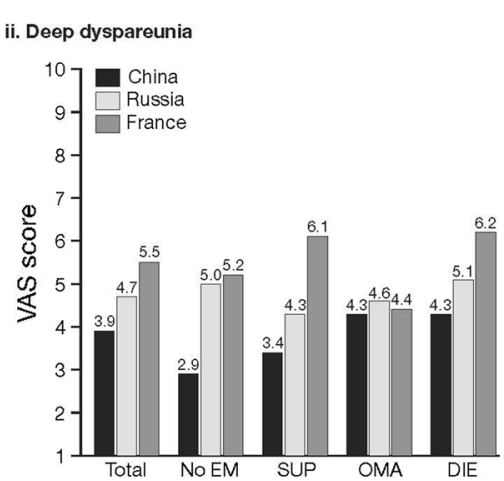

iii. Chronic non-cyclic pelvic pain

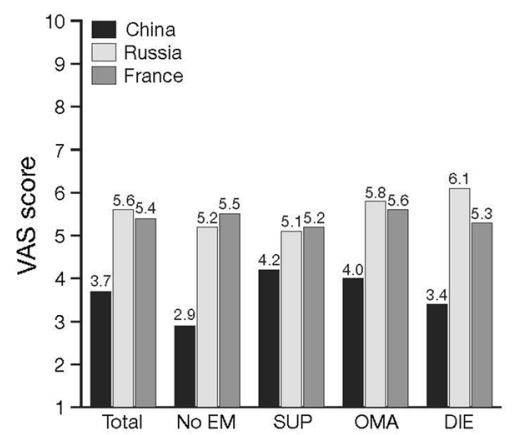

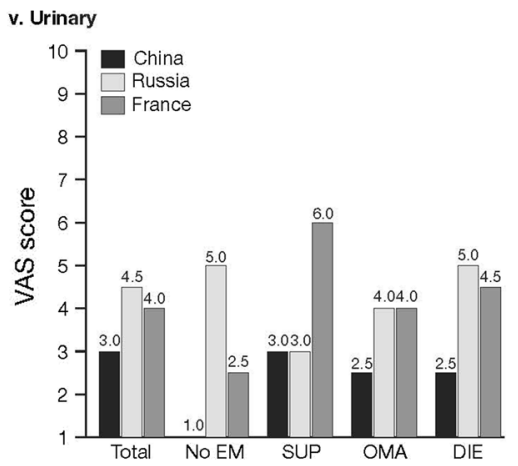

Fig. 1 continued

countries and phenotypes, their intensity differed largely according to country but not to phenotype.

\section{Other Variables}

Living or working in a busy area was recorded for $96.7 \%$ of patients from Russia, $89.0 \%$ from France, and $80.6 \%$ from China (France vs Russia, $\quad P<0.0008$; China vs France, $P=0.0159)$. Living or working in a smoky atmosphere was reported by $54.7 \%$ of patients from Russia, $22.6 \%$ from China, and 14.4\% from France (France vs Russia, $P<0.0001$; China vs France, $P=0.0267)$. In Russia and China, $92.2 \%$ and $89.5 \%$ of patients had been breastfed, respectively, compared with only $52.0 \%$ of patients from France. Finally, the mean (95\% CI) units of alcohol consumed per week were $0.68(0.58-0.78)$ for the total population $(N=988)$, with $0.20(0.12-0.28)$ for China, 1.03 (0.88-1.17) for Russia, and 1.63 (1.20-2.06) for France.

\section{DISCUSSION}

This multi-country, case-control study demonstrates important wide-ranging clinical and environmental factors that may be associated with DIE or OMA, compared with SUP and no endometriosis, in women who had recently undergone surgery for a benign gynecologic indication across three diverse regions. This is the first study, to our knowledge, to examine the relationship between such factors and endometriosis, and supports the theory that DIE and OMA have complex, multifaceted origins. The data highlight interesting regional differences, 
potentially influenced by health care and cultural practices specific to the local environment, in the diagnosis, symptomatology, and treatment practices of endometriosis.

Pain reporting varied between countries, possibly related to cultural influences, rather than actual differences in pain experienced. Indeed, most (82\%) French patients reported that dysmenorrhea impacted their lives vs only $44 \%$ of Chinese patients. Furthermore, deep dyspareunia was more frequent in French women without endometriosis (50\%) than in Chinese women with endometriosis (15.4\%). These findings suggest potentially different health care experiences and/ or expectations between patients from different regions. In addition, multiple studies suggest that cultural norms may influence individual conceptualization of pain and affect health-seeking behavior [26-28]. Although French patients reported more pain, they also tolerated longer duration between pain and treatment, which may reveal differences in treatment acceptability and/or health care system efficiencies.

Studies of Western patients with endometriosis report infertility rates of $30-50 \%$ [29]. However, $64.2 \%$ of Russian patients in our study reported infertility, vs $32.5 \%$ and $28.2 \%$ in France and China, respectively. The participating Russian centers are specialists in fertility treatment, suggesting that infertility rates seen in Russian patients, particularly with SUP histology (86\% of Russian SUP patients had infertility), may have been affected by referral biases. We hypothesize that infertility was the main indication for surgery among the controls/SUP cases (and tubal ligation was the main indication in other prospective cohorts), and speculate that only the best cases of infertility (i.e., young patients with good ovarian reserve) are operated on; other patients with poor infertility prognosis should receive assisted reproductive technologies without surgery.

The key strengths of this study are the inclusion of many patients $(N=1008)$ from three ethnically, culturally, socially, and economically different countries. In addition, each patient had been histologically diagnosed according to endometriosis phenotype, and all patients without endometriosis had been surgically explored to exclude asymptomatic endometriosis. To avoid recruitment bias, all consecutive patients who met the eligibility criteria during the specified period were included. To overcome the limitations of selecting a control group for patients with endometriosis [24], a case-control design was used to enable identification of associated factors and to avoid under-representation of DIE patients. All women included had recently undergone surgery for a benign gynecologic indication; however, any non-endometriosis pathology-benign ovarian cyst, uterine myoma, salpingitis, polycystic ovary syndrome, and tubal infertility treatment-was not taken into account when analyzing factors associated with endometriosis. Clinical presentation was chosen, as endometriosis is a heterogeneous disease with three different entities: SUP, OMA, and DIE [30]. The two main benefits for this approach are that treatment modalities are decided according to the clinical appearance of endometriotic lesions; and identifying risk factors for endometriosis contribute to reducing the delay for the diagnosis especially for the most severe phenotypes (OMA and DIE). The difficulties and limitations of this approach are that the three phenotypes can be present in the same patient [31]. Some specific study limitations exist. Data collection occurred at the post-operative visit when patients received the outcome of their surgical investigation. Patient behavior can 
change-particularly in the short termfollowing a clinical diagnosis $[32,33]$, and we cannot rule out the possibility that some patient responses regarding current behaviors were influenced by their surgery results. This might partly explain why only predictable factors (e.g., factors of diagnosis) were associated with OMA and/or DIE and not etiologic factors. Ideally, these data would have been collected prior to revealing the surgery results. In addition, a large quantity of data was collected retrospectively at the study visit, which makes causality and temporality difficult to assess, and is subject to recall bias.

The main objective of this study was not inter-country comparison. Thus, no formal monitoring of translations or assessment of literal translation accuracy across sites was carried out; however, translations were carried out at a country level, so translation accuracy and cultural competencies can be assumed. Low patient numbers in national groups by endometriosis type limit both inter- and intra-country comparisons; although numeric within-country differences were noted across endometriosis types, few were significant. Nevertheless, the importance of our findings should not be underestimated.

\section{CONCLUSION}

In conclusion, we show substantial differences in the symptoms and management of endometriosis phenotypes across three diverse countries, which suggest that this multifactorial, complex condition cannot be generalized on a global scale. Larger studies, taking into account geographic, cultural, and health care differences between patients, are required to confirm the initial findings reported here, with the goal of assisting investigators in achieving earlier patient risk stratification and diagnosis within routine clinical practice.

\section{ACKNOWLEDGMENTS}

Sponsorship, article processing charges and the open access fee for this study were funded by Ipsen. Writing assistance was provided by Philippa Cates and Helene Wellington, Mudskipper Business Ltd, and funded by Ipsen. All named authors meet the International Committee of Medical Journal Editors (ICMJE) criteria for authorship for this manuscript, take responsibility for the integrity of the work as a whole, and have given final approval for the version to be published.

Participation in study design [all authors], execution [all authors], statistical analysis [Pascal Maisonobe], manuscript drafting and critical discussion [all named authors].

Disclosures. P Maisonobe is an employee of Ipsen. P. Cabri is an employee of Ipsen. C. Chapron, J.-H. Lang, J.-H. Leng, Y. Zhou, X. Zhang, M. Xue, A. Popov and V. Romanov have nothing to disclose.

Compliance with Ethics Guidelines. All procedures followed were in accordance with the ethical standards of the responsible committee on human experimentation (institutional and national) and with the Helsinki Declaration of 1964, as revised in 2013. Patients provided written informed consent to allow their medical data to be collected, analyzed, and shared with regulatory authorities. The study identifier for clinicaltrials.gov is NCT01351051. Prior to initiating the study, the investigator/ institution had approval from the Independent Ethics Committee/Institutional Review Board as applicable in the country of study 
Open Access. This article is distributed under the terms of the Creative Commons Attribution-NonCommercial 4.0 International License (http://creativecommons.org/licenses/ by-nc/4.0/), which permits any noncommercial use, distribution, and reproduction in any medium, provided you give appropriate credit to the original author(s) and the source, provide a link to the Creative Commons license, and indicate if changes were made.

\section{REFERENCES}

1. Sampson JA. Metastatic or embolic endometriosis due to premenstrual dissemination of endometrial tissue into the peritoneal cavity. Am J Obstet Gynecol. 1927;3:93-110.

2. Buck Louis GM, Hediger ML, Peterson CM, Croughan M, Sundaram R, Stanford J, et al. Incidence of endometriosis by study population and diagnostic method: the ENDO study. Fertil Steril. 2011;96:360-5.

3. Morassutto C, Monasta L, Ricci G, Barbone F, Ronfani L. Incidence and estimated prevalence of endometriosis and adenomyosis in Northeast Italy: a data linkage study. PLoS ONE. 2016;11:e0154227.

4. Brawn J, Morotti M, Zondervan KT, Becker CM, Vincent K. Central changes associated with chronic pelvic pain and endometriosis. Hum Reprod Update. 2014;20:737-47.

5. de Ziegler D, Borghese B, Chapron C. Endometriosis and infertility: pathophysiology and management. Lancet. 2010;376:730-8.

6. Sinaii N, Plumb K, Cotton L, Lambert A, Kennedy S, Zondervan $\mathrm{K}$, et al. Differences in characteristics among 1,000 women with endometriosis based on extent of disease. Fertil Steril. 2008;89:538-45.

7. Nnoaham KE, Hummelshoj L, Webster P, D'Hooghe T, de Cicco Nardone F, de Cicco Nardone C, et al. Impact of endometriosis on quality of life and work productivity: a multicenter study across ten countries. Fertil Steril. 2011;96:366-73.

8. Hudelist G, Fritzer N, Thomas A, Niehues C, Oppelt $\mathrm{P}$, Haas D, et al. Diagnostic delay for endometriosis in Austria and Germany: causes and possible consequences. Hum Reprod. 2012;27:3412-6.
9. Vercellini $\mathrm{P}$, Viganò $\mathrm{P}$, Somigliana $\mathrm{E}$, Fedele L. Endometriosis: pathogenesis and treatment. Nat Rev Endocrinol. 2014;10:261-75.

10. Burney RO, Talbi S, Hamilton AE, Vo KC, Nyegaard $M$, Nezhat CR, et al. Gene expression analysis of endometrium reveals progesterone resistance and candidate susceptibility genes in women with endometriosis. Endocrinology. 2007;148:3814-26.

11. Santulli P, Borghese B, Noël JC, Fayt I, Anaf V, de Ziegler D, et al. Hormonal therapy deregulates prostaglandin-endoperoxidase synthase 2 (PTGS2) expression in endometriotic tissues. J Clin Endocrinol Metab. 2014;99:881-90.

12. Santulli P, Chouzenoux S, Fiorese M, Marcellin L, Lemarechal $\mathrm{H}$, Millischer $\mathrm{AE}$, et al. Protein oxidative stress markers in peritoneal fluids of women with deep infiltrating endometriosis are increased. Hum Reprod. 2015;30:49-60.

13. Leconte $M$, Nicco $C$, Ngô $C$, Chéreau C, Chouzenoux S, Marut W, et al. The mTOR/AKT inhibitor temsirolimus prevents deep infiltrating endometriosis in mice. Am J Pathol. 2011;179:880-9.

14. Ngô C, Nicco C, Leconte M, Chéreau C, Arkwright $\mathrm{S}$, Vacher-Lavenu MC, et al. Protein kinase inhibitors can control the progression of endometriosis in vitro and in vivo. J Pathol. 2010;222:148-57.

15. Borghese B, Tost J, de Surville M, Busato F, Letourneur F, Mondon F, et al. Identification of susceptibility genes for peritoneal, ovarian, and deep infiltrating endometriosis using a pooled sample-based genome-wide association study. Biomed Res Int. 2015;2015:461024.

16. Nyholt DR, Low SK, Anderson CA, Painter JN, Uno $\mathrm{S}$, Morris AP, et al. Genome-wide association meta-analysis identifies new endometriosis risk loci. Nat Genet. 2012;44:1355-9.

17. Pagliardini L, Gentilini D, Vigano' $\mathrm{P}$, Panina-Bordignon $\mathrm{P}$, Busacca $\mathrm{M}$, Candiani $\mathrm{M}$, et al. An Italian association study and meta-analysis with previous GWAS confirm WNT4, CDKN2BAS and FN1 as the first identified susceptibility loci for endometriosis. J Med Genet. 2013;50:43-6.

18. Borghese B, Barbaux S, Mondon F, Santulli P, Pierre G, Vinci $G$, et al. Research resource: genome-wide profiling of methylated promoters in endometriosis reveals a subtelomeric location of hypermethylation. Mol Endocrinol. 2010;24:1872-85.

19. Umezawa M, Sakata C, Tanaka N, Tabata M, Takeda $\mathrm{K}$, Ihara T, et al. Pathological study for the effects of 
in utero and postnatal exposure to diesel exhaust on a rat endometriosis model. J Toxicol Sci. 2011;36:493-8.

20. Chapron C, Souza C, Borghese B, Lafay-Pillet MC, Santulli P, Bijaoui G, et al. Oral contraceptives and endometriosis: the past use of oral contraceptives for treating severe primary dysmenorrhea is associated with endometriosis, especially deep infiltrating endometriosis. Hum Reprod. 2011;26:2028-35.

21. Chapron C, Chiodo I, Leconte M, Amsellem-Ouazana D, Chopin N, Borghese B, et al. Severe ureteral endometriosis: the intrinsic type is not so rare after complete surgical exeresis of deep endometriotic lesions. Fertil Steril. 2010;93:2115-20.

22. Koninckx PR, Martin DC. Deep endometriosis: a consequence of infiltration or retraction or possibly adenomyosis externa? Fertil Steril. 1992;58:924-8.

23. Koninckx PR. Is mild endometriosis a condition occurring intermittently in all women? Hum Reprod. 1994;9:2202-5.

24. Holt VL, Weiss NS. Recommendations for the design of epidemiologic studies of endometriosis. Epidemiology. 2000;11:654-9.

25. Hosmer DW, Lemeshow S. Applied Logistic Regression. New York: Wiley; 2000.

26. Kwok W, Bhuvanakrishna T. The relationship between ethnicity and the pain experience of cancer patients: a systematic review. Indian J Palliat Care. 2014;20:194-200.
27. Campbell CM, Edwards RR. Ethnic differences in pain and pain management. Pain Manag. 2012;2:219-30.

28. Frisch S. Perceptions of pain. Cultural differences add to the challenge of treating patients' pain. Minn Med. 2014;97:14-6.

29. Bulletti C, Coccia ME, Battistoni S, Borini A. Endometriosis and infertility. J Assist Reprod Genet. 2010;27:441-7.

30. Nisolle M, Donnez J. Peritoneal endometriosis, ovarian endometriosis, and adenomyotic nodules of the rectovaginal septum are three different entities. Fertil Steril. 1997;68:585-96.

31. Somigliana E, Vercellini P, Gattei U, Chopin N, Chiodo I, Chapron C. Bladder endometriosis: getting closer and closer to the unifying metastatic hypothesis. Fertil Steril. 2007;87:1287-90.

32. Kuznetsov L, Simmons RK, Sutton S, Kinmonth AL, Griffin SJ, Hardeman W. Predictors of change in objectively measured and self-reported health behaviours among individuals with recently diagnosed type 2 diabetes: longitudinal results from the ADDITION-Plus trial cohort. Int J Behav Nutr Phys Act. 2013;10:118.

33. Satia JA, Campbell MK, Galanko JA, James A, Carr C, Sandler RS. Longitudinal changes in lifestyle behaviors and health status in colon cancer survivors. Cancer Epidemiol Biomark Prev. 2004;13:1022-31. 